\title{
Alimentacão de bezerros com extrato hidrossolúvel de soja. HI. Produção de anticorpos e distúrbios intestinais
}

\section{Feeding calves with soybean hydrosoluble extract. II. Antibody production and effects upon intestinal villosity}

\author{
Sergio Novita ESTEVES ${ }^{\prime}$; Marilene Del Vuono Camargo PENTEADO²; Enrico Lippi \\ ORTOLANI ${ }^{3}$; Idércio Luiz SINHORINI ${ }^{4}$
}

CORRESPONDENCE TO:

Sergio Novita Esteves

Emprasa Brasileira de Pesquisa

Agropecuáría - EMBRAPA

Unidado de Execuçáo de Pesquisa de

Ambiro Estadual

Calxa Postal 339

13560-000 - SaO Carlos - SP - Brasil

e-mail: serglo@copse.embrapa.br

1 - EMBRAPA - SEO CEHOS - SP 2 - Faculdado de Ciéncias Farmacóuticas da USP - SP 3 - Departamento de Clinica Médica Faculdado Medicina Veterinária $\theta$ Faculdade Medicina Ve
Zootecnia da USP - SP 4 - Departamento de Patologia Faculdade de Medicina Veterinária $\theta$ Zootecnia da USP - SP

\section{RESUMO}

O objetivo do trabalho foi avaliar a substituição total do sucedâneo lácteo à base de proteína de leite (SL) por extrato hidrossolúvel de soja (EHS) na alimentação de bezerros Holandeses machos, com idade média inicial de cinco dias. Os bezerros alimentados com EHS a partir do $5^{\circ}$ dia de vida apresentaram, com o desenvolver do experimento, perda de peso pronunciada, diarréia, letargia, caquexia e, nos estágios terminais, desidratação e hipoproteinemia. Apresentaram, ainda, atrofia das vilosidades intestinais e produção de anticorpos no soro contra a proteína do EHS, indicação de que os bezerros estavam padecendo de uma reação alérgica à proteína de soja, enquanto os bezerros do grupo-controle apresentaram-se com desenvolvimento corporal normal. Os bezerros alimentados com EHS apresentaram diminuição visível das gorduras presentes no tecido subcutâneo, omento, epíplon e da gordura perirenal. No abomaso, a principal alteração verificada foi a falta de formação do coágulo do EHS ingerido.

UNITERMOS: Alimentação; Bezerros; Soja; Distúrbios.

\section{INTRODUÇĀO}

$\mathrm{O}$ "leite de soja" corresponde a um extrato aquoso dos grãos moídos e tratados com aquecimento, e a sua utilização em substituição ao leite de vaca tem sido recomendada nos programas de desaleitamento, devido às propriedades físico-químicas semelhantes ao leite de vaca, além de ser de fácil obtenção e preparo e ter baixo custo (Tiesenhausen ${ }^{13}, 1971$ ), apesar de algumas vezes ocorrerem transtornos digestivos juntamente com menor desenvolvimento do animal. Os sucedâneos lácteos que contêm proteína de soja apresentam alguns fatores que têm sido relatados como causadores do baixo desenvolvimento dos animais, como antienzimas inibidoras da tripsina e da quimotripsina (Gorrill; Thomas $^{3}, 1967$ ), não formação de coágulo no abomaso (Roy et $\left.a l^{8}, 1977\right)$, e reaçōes imunológicas em nível intestinal (Dawson et al. ${ }^{1}, 1988$ ). Bezerros alimentados com dietas contendo farinha de soja (Smith; Sissons $\left.{ }^{12}, 1975\right)$ ou farinha de soja aquecida (Dawson et al. ${ }^{1}, 1988$ ) produziram altos títulos séricos de anticorpos contra a proteína da soja, e foram correlacionados com o desenvolvimento de distúrbios digestivos. Alguns estudos têm revelado mudanças morfológicas na estrutura do intestino delgado de bezerros alimentados com proteína de soja (Silva ${ }^{9}, 1984$ ), como a atrofia das vilosidades intestinais, associando-lhe também fluxo anormal da digesta e altos títulos de anticorpos contra esta proteína.

Este trabalho teve por objetivo estudar as causas dos distúrbios gastrointestinais que podem ocorrer em bezerros recém-nascidos, alimentados com proteína de soja.

\section{MATERIAL E MÉTODO}

O experimento foi conduzido no Hospital Veterinário (Hovet) da Faculdade de Medicina Veterinária e Zootecnia Universidade da São Paulo (FMVZ-USP), utilizando-se 7 bezerros Holandeses machos, de 4 a 6 dias de idade, mantidos em baias individuais e distribuídos casualmente entre os tratamentos.

A partir do $5^{0}$ dia de vida, os animais do tratamento I receberam sucedâneo lácteo comercial (SL), e os do tratamento III receberam extrato hidrossolúvel de soja (EHS), na quantidade de 4 litros por dia, feno de "coast-cross", ração comercial peletizada própria para bezerros e água à vontade. 0 
SL utilizado neste experimento continha como única fonte de proteína, a originária do leite, sendo preparado diariamente na proporçāo de 200 gramas de SL para 2 litros de água morna.

Para o preparo do EHS, utilizou-se $1 \mathrm{~kg}$ de grão de soja moído e misturado em 6 litros de água, colocado em autoclave a $120^{\circ} \mathrm{C}$ por $20 \mathrm{~min}$. A seguir, coava-se a mistura e era adicionada água morna para se manter uma proporção de 1:10. A composiçāo química dos sucedâneos está demonstrada na Tab. 1 .

Tabela 1

Composição química dos substitutos lácteos hidratados. São Paulo, abril a novembro de 1987.

\begin{tabular}{l|c|c}
\hline \multicolumn{1}{c|}{ Ingredientes } & SL & EFS \\
\hline Extrato seco total (\%) & $\mathbf{8 , 3 8}$ & 3,11 \\
Proteína bruta (\%) & 2,05 & 1,39 \\
Matéria mineral (\%) & 0,70 & 0,25 \\
Energia bruta (cal/g) & 307,90 & 15,32 \\
Inibidor da tripsina (U.I.T./mg) & - & 1,2 a 3,3 \\
Atividade aglutinante & - & $1: 5,7$ \\
\hline
\end{tabular}

No tratamento III, os animais mostraram com o desenvolver do experimento sinais de depressāo e debilidade no estado corpóreo, optando-se pelo sacrifício dos mesmos por eletrocução. Paralelamente, outro animal na mesma idade, ingerindo SL, foi sacrificado para fins de comparação. No exame necroscópico retirou-se imediatamente um segmento do intestino delgado, distante $50 \mathrm{~cm}$ do abomaso, fixado em formol a $10 \%$, e que foi enviado ao laboratório de histopatologia do Departamento de Patologia da FMVZ-USP. Após um período mínimo de 24 horas, seguiu-se a desidratação em soluções de concentrações crescentes de álcool, diafanização em xilol e inclusão em parafina, de onde foram obtidos cortes de 5 micra de espessura e corados pelo método da Hematoxilina-Eosina. $\mathrm{O}$ estudo morfológico por microscopia com luz comum, bem como a respectiva documentação fotográfica, foi realizado com auxílio de fotomicroscópio Leitz Ortolux. As medidas de altura das vilosidades intestinais foram realizadas nas fotomicrografias, e para cada bezerro foram medidas vinte vilosidades. A proteína sérica total foi determinada conforme técnica descrita por Gornall et al. ${ }^{2}$ (1949), e os anticorpos no soro contra a proteína de soja, pelo método de hemoaglutinação passiva descrito por Herbert $^{4}$ (1967).

Os resultados foram estudados por meio de análise de variância, e as médias comparadas pelo teste de Fisher (Singer; Andrade $^{\text {(0) }}$ 1986).

\section{RESULTADOS E DISCUSSÃO}

Os bezerros que ingeriram EHS, após um ou dois dias de aleitamento, apresentaram dificuldade em aceitá-lo no balde, sendo oferecido, então, com mamadeira, nāo se verificando diminuição no consumo desta dieta líquida. Smith et al." (1970), em experimento semelhante, verificaram que os bezerros foram relutantes ou até rejeitaram o aleitamento com farinha de soja após duas ou três alimentações. Esses animais ainda apresentaram as fezes semilíquidas, que se tornaram progressivamente mais fétidas e diarréicas, apatia, dificuldade locomotora, desidratação, perda de peso e emaciação, concordantes com Gorril; Thomas ${ }^{3}$ (1967) e Silva ${ }^{9}$ (1984).

Os bezerros alimentados com SL ganharam em média 67,7 $\mathrm{g} / \mathrm{dia}$, e os bezerros alimentados com EHS perderam em média $540 \mathrm{~g} /$ dia, até a data do sacrifício, ocorrida 12 dias após o início do experimento. Esta perda de peso pode ser relacionada à habilidade inferior do sistema digestivo em digerir e absorver os nutrientes, à presença do fator inibidor da tripsina, ou à redução das secreções proteolíticas do trato digestivo, conforme descrito (Kakade et al. ${ }^{5}, 1976$; Roy et al. ${ }^{8}, 1977$ ).

$\mathrm{O}$ valor médio de proteína sérica total obtido no dia do sacrifício dos animais que receberam o SL foi de $6,13 \mathrm{~g} \%$ e de $4,79 \mathrm{~g} \%$ para os que receberam o EHS, e diferiu significativamente $(p<0,05)$. Esses resultados demonstram que os bezerros que receberam o EHS apresentavam um quadro de hipoproteinemia, e estāo concordantes com os resultados obtidos por Ortolani $^{6}$ (1983). Estes animais desenvolveram também reação positiva de anticorpos contra a proteína de soja, que variou de 1:80 $¥ 7: 320$, enquanto os animais que receberam SL apresentaram reação negativa. Esses resultados concordam com os obtidos por Smith; Sissons ${ }^{12}$ (1975) e Pedersen; Sissons ${ }^{7}$ (1984), os quais verificaram títulos de anticorpos no soro, variando de 1:5120 e 1:160, respectivamente.

O exame histopatológico dos segmentos do intestino delgado dos bezerros alimentados com EHS revelou diminuição significativa $(\mathrm{p}<0,05)$ no tamanho das vilosidades intestinais, em relação aos bezerros alimentados com SL $(6,17$ $\mathrm{cm} \times 2,32 \mathrm{~cm}$ ).

As fotomicrografias obtidas de cortes de intestinos de bezerros que ingeriram SL se apresentaram normais (Fig. 1), enquanto os animais que receberam EHS apresentaram as vilosidades intestinais atrofiadas (Fig. 2), confirmando as observações feitas por Pedersen; Sissons ${ }^{7}$ (1984) e Silva" (1984).

A reação positiva de anticorpos no soro dos bezerros que ingeriram o EHS e a atrofia observada nas vilosidades intestinais indicam que o EHS causou reação alérgica nos bezerros, e estão concordantes com as observações obtidas por Pedersen; Sissons ${ }^{7}$ (1984) e Dawson et al.' (1988).

$\mathrm{Na}$ necrópsia dos animais alimentados com proteína de soja, foi verificada diminuição visível na gordura subcutânea do omento, do epíplon, demonstrando que os animais apresentavam depleção dos depósitos de gordura. Nestes animais também se verificou diminuição significativa de gordura peri-renal, quando comparados com os bezerros do grupo-controle. No exame do rúmen, não se notou nenhuma alteração, apenas as papilas ruminais estavam pouco 
ESTEVES, S.N.; PENTEADO, M.D.V.C.; ORTOLANI, E.L.; SINHORINI, I.L. Alimentação de bezerros com extrato hidrossolúvel de soja. II. Produção de anticorpos e distúrbios intestinais. Braz. J. vet. Res. anim. Sci. Sāo Paulo, v.33, supl., p.286-289, 1996.

desenvolvidas, o que é normal em bezerros que recebem somente alimentação líquida. Os animais que ingeriram o EHS apresentaram no conteúdo ruminal maior quantidade de corpos estranhos, como pêlos e serragem, do que os animais do grupocontrole, evidenciando a parorexia. No abomaso, a principal alteração verificada foi a falta de formação do coágulo do EHS ingerido pelos bezerros. Nos intestinos, a mucosa apresentavase normal, com poucas áreas hemorrágicas, e a digesta mais fluida nos bezerros que ingeriram EHS.

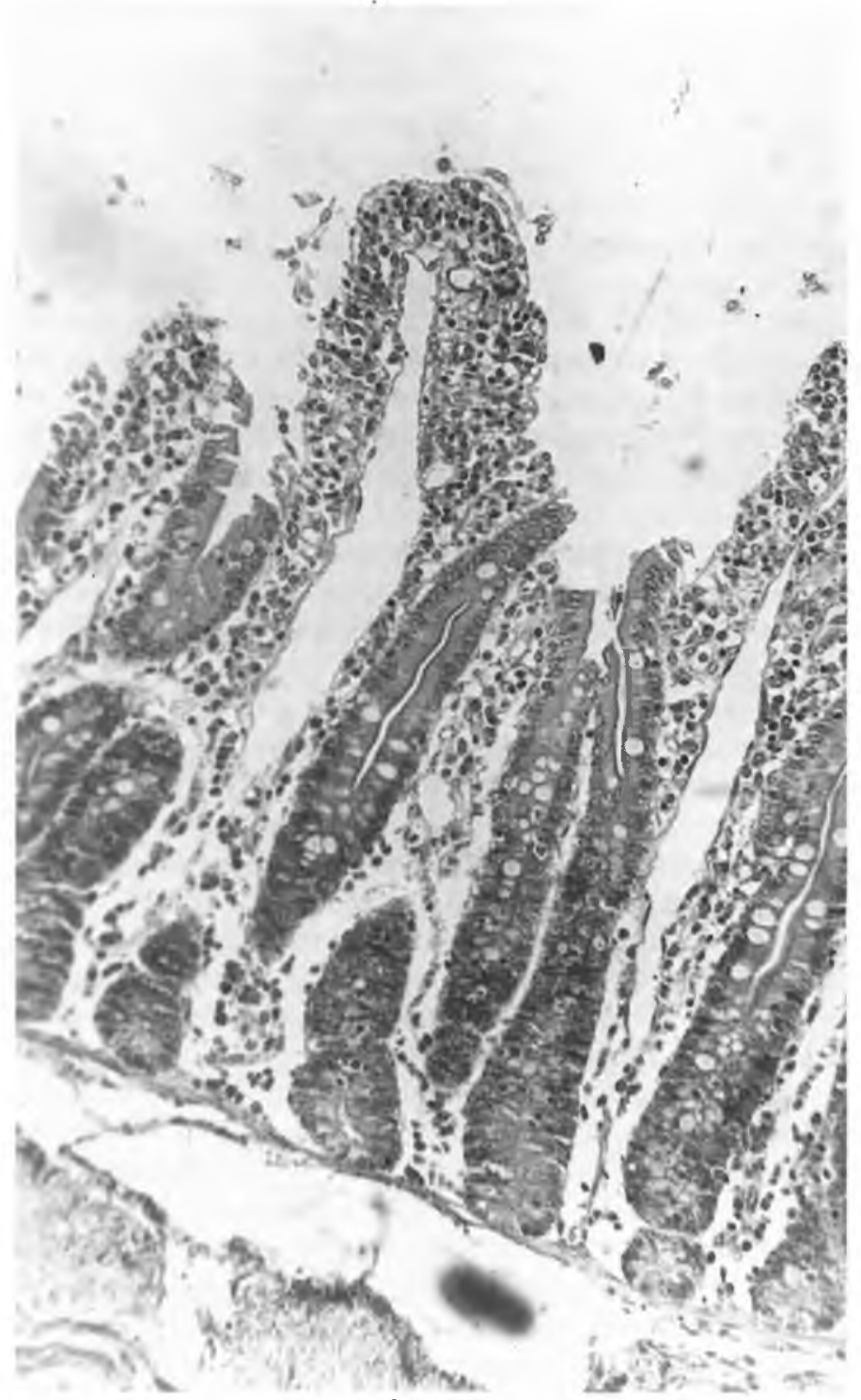

Figura 1

Fołomicrografia de corte histológico de intestino delgado de bezerro do grupo-controle, corada por meio do método Hematoxilina-Eosina (aumento 125 x).

\section{CONCLUSÕES}

EHS não deve ser fornecido a bezerros, a partir do $5^{\circ}$ dia de idade, devido a causar diarréia, letargia, caquexia, desidratação, hipoproteinemia, atrofia das vilosidades intestinais e produção de anticorpos no soro contra a proteína da soja, indicação de que os bezerros estavam sofrendo de uma reação alérgica a esta proteína. Ao exame necroscópico destes bezerros, observou-se diminuição na gordura subcutânea, do omento e epíplon, e na gordura peri-renal, e no abomaso não houve formação de coágulo.

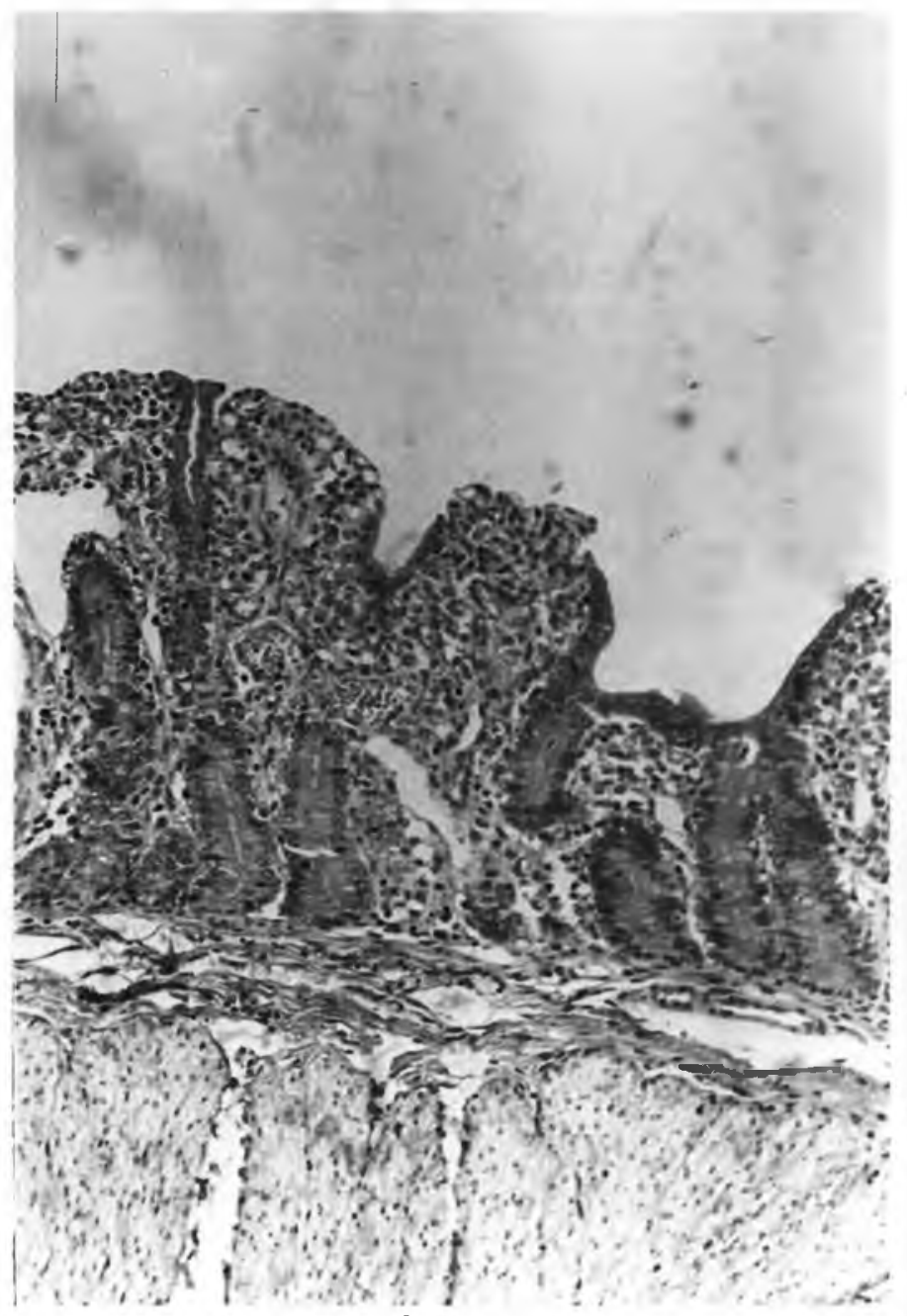

Figura 2

Fotomicrografia de corte histológico de intestino delgado de bezerro tratado com extrato hidrossolúvel de soja, corada por meio do método HematoxilinaEosina (aumento $125 \mathrm{x}$ ). 
ESTEVES, S.N.; PENTEADO, M.D.V.C.; ORTOLANI, E.L.; SiNHORINI, I.L. Alimentaçāo de bezerros com extrato hidrossolúvel de soja. II. Produção de anticorpos e distúrbios intestinais. Braz. J. vet. Res. anim. Sci., São Paulo, v.33, supl., p.286-289, 1996.

\section{SUMMARY}

The aim of this investigation was to study the total replacement of milk substitute (SL) for soybean hydrosoluble extract (EHS) in feeding 5-day-old Holstein male calves. Calves fed with EHS from the $5^{\text {th }}$ day of age showed, throughout the experiment, weight loss, diarrhea, lethargy, cachexia and at the final stage, dehydration and hypoproteinemia. In addition, these calves had intestinal villosity atrophy and sera antibody production against the EHS protein, indicating they were suffering from an allergic reaction, while the control group calves showed normal development. The calves fed with EHS showed visible decrease of subcutaneous fat, omentum, epiploon and perirenal fat. The main change observed in the abomasum was absence of clot formation.

UNITERMS: Feeding; Calves; Soybeans; Disorders.

\section{REFERÊNCIAS BIBLIOGRÁFICAS}

1-DAWSON, D.P.; MORRILL, J.L.; REDDY, P.G.; MINOCHA, H.C. Soy protein concentrate and heated soy flours as protein sources in milk replacers for preruminant calves. Journal of Dairy Science, v. 71, n.5, p.1301-9, 1988

2-GORNALL, A.G.; BARDAWILL, C.J.; DAVID, M.M. Determination of serum proteins by means of the biuret reaction. Journal of Biological Chemistry, v.177, p. $751-66,1949$

3-GORRILL. A.D.I..; THOMAS. J.W. Body weight changes, pancreas size and enzyme activity, and proteolytic cnzime activity and protein digestion in intestinal contents from calves fed soybean and milk protein diets. Journal of Nutrition. v.92, n.2, p.215-23, 1967

4-HERBERT, W.J. Passive haemagglutination, In: WEJR, D.M., ed. Handbook of experimental immunology. Oxford, Blackwell, 1967. p.720-74.

5-KAKADE, M.L.; THOMPSON, R.M.; ENGELTAD, W.E.; BEHRENS, G.C.; YODER. R.D.; CRANE, F.M. Failure of soybean trypsin inhibitor to exert deleterious effect in calves. Journal of Dairy Science, v.58, n.8, p. 1484-9, 1976.

6-ORTOLANI. E.L. Insuficiência pancreática exócrina em bezerros determinada pela ingestão prolongada de leite de soja como sucedâneo lácteo. In: SEMANA DE VETERINÁrIA, 2., São Palilo, 1983. Anais. São Paulo, Faculdade de Medicina Veterinária e Zootecnia da Universidade de Sāo Paulo, 1983. p.73.

7-PEDERSEN. H.E.: SISSONS. J.W. Effect of antigenic soybean protein on the physiology and morphology of the gut in the preruminant calf. Canadian Journal of Science, v. 64, p. 183-4, 1984 (Supplement 1).

8-ROY, J.H.B.; STOBO, I.J.F ; SHOTTON, S.M.: GANDERTON, P.: GILLIES, C.M. The nutritive value of non-milk proteins for the preruminant calf. The effect of replacement of milk protein by soybean flour or fish-protein concentrate. British Journal of Nutrition, v.38, p. 167-87, 1977

9-SILVA A.G. Factors affecting utilization of soybean proteins included in milk replacers for young calves. East Lansing, 1984.97p. PhD Thesis, Michigan State University.

10-SINGER. J.M.; ANDRADE, D.F. Análise de dados Iongitudinais. Campinas, IMECC-UNICAMP. 1986, $106 \mathrm{p}$.

1]-SMITH, R.H.: HIL.L. W. B.: SISSONS, J.W. Effect of diets containing soy products on the passage of digesta through the alimentary tract of the preruminant call. Proceedings of the Nutrition Society, v.29, n.1, p.2A, 1970

12-SMITH, R.H.; SISSONS, J.W. The effect of different feeds, including those containing soybean products, on the passage of digesta from the abomasum of the preruminant calf. British Journal of Nutrition, v.33, n.3, p. 329-49, 1975

13-TIESENHAUSEN, I.M.E.V. Substituiçāo do leite de vaca integral pelo leite de soja na alimentaça de bezerros. In: REUNIÃO DA SOCIEDADE BRASILEIRA DE ZOOTECNIA, 8, 1971. Rio de Janeiro. Anais. Rio de Janeiro. Sociedade Brasileira de Zootecnia, 1971. p. 166-7. 